\title{
Napsin A is negatively associated with EMT-mediated EGFR-TKI resistance in lung cancer cells
}

\author{
LINSHUI ZHOU* ${ }^{*}$ XIN LV* ${ }^{*}$ JUNCHAO YANG, YUANHONG ZHU, ZHEN WANG and TINGZHEN XU \\ Department of Respiratory Medicine, The First Affiliated Hospital of Zhejiang Chinese Medicine University, \\ Hangzhou, Zhejiang 310006, P.R. China
}

Received May 4, 2017; Accepted November 2, 2017

DOI: $10.3892 / \mathrm{mmr} .2018 .9075$

\begin{abstract}
Epidermal growth factor receptor tyrosine kinase inhibitors (EGFR-TKI) have been used as a standard therapy for patients with lung cancer with EGFR-activating mutations. Epithelial-mesenchymal transition (EMT) has been reported to be associated with the development of EGFR-TKI resistance, which limits the clinical efficacy of EGFR-TKI. Therefore, investigating the resistance-associated mechanism is required in order to elucidate an effective therapeutic approach to enhance the sensitivity of lung cancer to EGFR-TKI. In the present study, EGFR-TKI erlotinib-sensitive H358, H322 and H441 lung cancer cells, erlotinib-moderately sensitive A549 cells, and erlotinib-insensitive HCC827 cells with EGFR-mutation (exon 19 deletion) were used to detect the mRNA and protein expression of the EMT-associated proteins E-cadherin and vimentin, and napsin A, by reverse transcription-quantitative polymerase chain reaction analysis and western blotting. It was observed that the E-cadherin expression level in erlotinib-sensitive cells was increased compared with the moderately sensitive A549 cells and HCC827 cells; however, vimentin exhibited opposite expression, suggesting a correlation between EMT and erlotinib sensitivity in lung cancer cells. The napsin A expression level was observed to be positively associated with erlotinib sensitivity. In addition, napsin A highly-expressingH322 cells were used and napsin A-silenced cells were constructed using small interfering RNA (siRNA) technology, and were induced by transforming growth factor (TGF)- $\beta 1$. It was observed that TGF- $\beta 1$ partially induced the alterations in E-cadherin and vimentin expression and the
\end{abstract}

Correspondence to: Mr. Zhen Wang, Department of Respiratory Medicine, The First Affiliated Hospital of Zhejiang Chinese Medicine University, 54 Post and Telecommunications Road, Hangzhou, Zhejiang 310006, P.R. China

E-mail: zzwang88@126.com

${ }^{*}$ Contributed equally

Key words: napsin A, lung cancer, epidermal growth factor receptor tyrosine kinase inhibitors, drug sensitivity, epithelial-mesenchymal transition occurrence of EMT in napsin A highly-expressing cells, while TGF- $\beta 1$ significantly induced EMT via downregulation of E-cadherin and upregulation of vimentin in napsin A-silenced cells; cell proliferation and apoptosis assays demonstrated that TGF- $\beta 1$ induced marked resistance to erlotinib in napsin A-silenced cells compared with napsin A-expression cells. These data indicated that napsin A expression may inhibit TGF- $\beta 1$-induced EMT and was negatively associated with EMT-mediated erlotinib resistance, suggesting that napsin A expression may improve the sensitivity of lung cancer cells to EGFR-TKI through the inhibition of EMT.

\section{Introduction}

Lung cancer is one of the most common malignant tumors in the world, exhibiting a high mortality rate due to abnormal cell proliferation and a high metastasis rate (1). Small-molecule epidermal growth factor receptor tyrosine kinase inhibitors (EGFR-TKI), including erlotinib, exert a marked clinical effect in lung cancer with EGFR-activating mutations, and have been used as a standard therapy in the patients with lung cancer $(2,3)$. However, the majority of patients develop drug resistance following a period of treatment with EGFR-TKI, which markedly limits the therapeutic efficacy of EGFR-TKI (4). Therefore, investigating the resistance-associated mechanism is required to explore an effective therapeutic approach to enhance the sensitivity of lung cancer to EGFR-TKI.

Epithelial-mesenchymal transition (EMT) is known to be a molecular mechanism underlying the acquisition of TKI resistance (5). Cells undergo morphological alterations from an epithelial phenotype to a mesenchymal phenotype during EMT, lose epithelial cell-cell adhesion and are able to move through the extracellular matrix, leading to increased proliferation, invasion and metastasis (6). EMT has been frequently reported to be activated during cancer metastasis in multiple types of human cancer $(7,8)$. EMT is characterized by the loss of cell adhesion molecules, including catenin and E-cadherin, and the acquisition of mesenchymal marker proteins including zinc finger protein SNAI1, fibronectin, type I collagen, and vimentin (9). EMT has been demonstrated to be involved in the sensitivity of cancer cells to conventional chemotherapies $(10,11)$. In addition, sensitivity to EGFR-TKI is additionally regulated by EMT in lung cancer cells (12). TGF- $\beta 1$ is frequently used to drive the EMT process and induce 
resistance to EGFR-TKI in lung cancer cells (13). Examining novel factors affecting EMT is important to prevent the development of EGFR-TKI resistance.

Napsin A has been identified to be a novel member of the aspartate protease family (14), and was observed to be correlated with the maturation of the spleen, kidney and lung, in addition to surfactant synthesis in the lung (15-17). Napsin A was demonstrated to be expressed in normal lung tissue and was detected in lung adenocarcinoma (18-20). It was observed that napsin A was negatively associated with the degree of transformation of cancer cells (20-22). Additionally, cells with low napsin A expression or without napsin A expression appear to be susceptible to EMT (23). The present study hypothesized that the expression of napsin A may affect EMT-mediated TKI resistance in lung cancer cells.

The present study employed a number of lung cancer cell lines, differentially-sensitive to the EGFR-TKI erlotinib. The expression of E-cadherin and vimentin, associated with EMT, in addition to napsin $\mathrm{A}$ was detected in lung cancer cells prior to and following the induction of TGF- $\beta 1$. Lung cancer H322 cells with high napsin A expression were selected for the investigation of the effect of napsin A silencing on the sensitivity of lung cancer cells to erlotinib, through TGF- $\beta 1$ induction. It was observed that napsin A-silenced cells exhibited increased resistance to erlotinib under the conditions of TGF- $\beta 1$ induction compared with napsin A-expression cells, suggesting that napsin A served an important role in the sensitivity of EMT-mediated resistant lung cancer cells to TKI.

\section{Materials and methods}

Cell culture and reagents. The lung cancer cell lines (H358, $\mathrm{H} 322, \mathrm{H} 441$, A549 and HCC827) were obtained from the American Type Culture Collection (Manassas, VA, USA)and were cultured in RPMI-1640 medium (Gibco; Thermo Fisher Scientific, Inc., Waltham, MA, USA) supplemented with $10 \%$ fetal bovine serum (Lonza Group, Ltd., Basel, Switzerland), $5 \mathrm{mmol} / \mathrm{l} \mathrm{L}$-glutamine, $5 \mathrm{mmol} / \mathrm{l}$ non-essential amino acids and $100 \mathrm{U} / \mathrm{ml}$ penicillin and streptomycin (Invitrogen; Thermo Fisher Scientific, Inc.), in a humidified $5 \% \mathrm{CO}_{2}$ incubator at $37^{\circ} \mathrm{C}$. Erlotinib (Tarceva ${ }^{\circledR}$ ) was purchased from Cayman Chemical Company (Ann Arbor, MI, USA). A 10-mmol/1 erlotinib stock solution was prepared in dimethyl sulfoxide (DMSO).

RNA interference for napsin A. siRNA against napsin A and the negative control were designed and chemically synthesized by Shanghai GenePharma Co., Ltd. (Shanghai, China). The target sequence of siRNA against napsin A was as follows: AATCTT AAACCCACTGAATGG. The small interference RNA of negative control (siCtrl): Sense, 5'-UUCUCCGAACGUGUC ACGUTT-3'; Antisense, 5'-ACGUGACACGUUCGGAGA ATT-3'. A total of $2 \times 10^{4} \mathrm{H} 322$ cells were seeded into each well of a 12 -well plate and were cultured to $80 \%$ confluence. $C$ ell transfections were performed using $100 \mathrm{nmol}$ siRNA and $5 \mu \mathrm{l}$ Lipofectamine ${ }^{\circledR} 2000$ (Invitrogen; Thermo Fisher Scientific, Inc.), according to the manufacturer's protocol. Cells were further cultured for $48 \mathrm{~h}$ following transfection, and cells were subsequently lysed and analyzed for the protein expression of napsin A by western blotting. In addition, cells were treated with $0,1,5,10$ and $15 \mathrm{ng} / \mathrm{ml}$ TGF- $\beta 1$ for $60 \mathrm{~h}$, and then cell proliferation and the EMT-associated protein levels were detected.

Reverse transcription-quantitative polymerase chain reaction $(R T-q P C R)$ analysis. Total RNA was extracted using an RNA isolation kit (A\&A Biotechnology, Gdynia, Poland), according to the manufacturer's protocol. cDNA was obtained by RT using the RevertAid ${ }^{\mathrm{TM}}$ First Strand cDNA synthesis kit (Fermentas, Thermo Fisher Scientific, Inc., Pittsburgh, PA, USA) and was amplified using a TaqMan ${ }^{\circledR}$ Gene Expression Assay (Applied biosystems, Thermo Fisher Scientific, Inc.) with fluorogenic Carboxyfluorescein-labeled probes using specific primers for target proteins. The specific primers for PCR were forward, 5'-GGATTGCAAATTCCTGCCATTC-3' and reverse, 5'-AACGTTGTCCCGGGTGTCA-3' for E-cadherin; forward, 5'-GGAAGGCGAGGAGAGCAGGATT-3' and reverse, 5'-TTCAAGGTCATCGTGATGCTGAGAAG-3' for vimentin; forward, 5'-GGAGCCTGAGGAGGCC-3' and reverse, 5'-GGACTTGGGATTAATGCG-3' for napsin A; and forward, 5'-GATCCCTCCAAAATCAAGTG-3' and reverse, 5'-GAGTCCTTCCACGATACCAA-3' for GAPDH. Real-time fluorescence detection was performed with the ABI PRISM 7700 Sequence Detector (Applied Biosystems, Thermo Fisher Scientific, Inc.). PCR involved 40 amplification cycles of $94^{\circ} \mathrm{C}$ for $10 \mathrm{sec}, 53^{\circ} \mathrm{C}$ for $30 \mathrm{sec}$ and $72^{\circ} \mathrm{C}$ for $40 \mathrm{sec}$, followed by final extension at $72^{\circ} \mathrm{C}$ for $10 \mathrm{~min}$. mRNA expression of target proteins was calculated using the formula $2^{\Delta \Delta \mathrm{Cq}}(24)$ and was normalized to the level of GAPDH. The relative mRNA level was presented as a percentage of the control.

Western blot analysis. Cells were cultured to $80 \%$ confluence. The cells were washed twice with PBS and proteins were extracted using M-PER Mammalian Protein Extraction Reagent (Pierce; Thermo Fisher Scientific, Inc.), according to the manufacturer's protocol. Following centrifugation at $12,000 \mathrm{x} \mathrm{g}$ for $10 \mathrm{~min}$, the supernatant was collected and quantified using a Bicinchoninic acid (BCA) quantification kit (Beyotime Institute of Biotechnology, Haimen, China). The proteins $(50 \mu \mathrm{g})$ were separated by SDS-PAGE on a $12 \%$ gel (Beijing Solarbio Science \& Technology Co., Ltd., Beijing, China) and transferred to polyvinylidene fluoride membranes (EMD Millipore, Billerica, MA, USA). The membranes were blocked with 5\% non-fat dried milk in TBS-Tween 20 for $1 \mathrm{~h}$, and incubated with specific primary antibodies overnight at $4^{\circ} \mathrm{C}$. Mouse monoclonal anti-E-cadherin (cat. no. sc-21791; 1:2,000; Santa Cruz Biotechnology, Inc., Dallas, TX, USA), mouse monoclonal anti-vimentin (cat. no. sc-6260; 1:2,000; Santa Cruz Biotechnology, Inc.), mouse monoclonal anti-N-cadherin (cat no. sc-8424; 1:2,000; Santa Cruz Biotechnology, Inc.), anti-GAPDH antibody (cat. no. sc-365062; 1:3,000; Santa Cruz Biotechnology, Inc.) and rabbit monoclonal anti-napsin A antibody (cat. no. ab133249; 1:10,000; Abcam, Cambridge, UK) were used, followed by horseradish peroxidase-conjugated secondary antibodies goat anti-mouse (cat no. sc-2005; 1:2,000; Santa Cruz Biotechnology, Inc.) and anti-rabbit immunoglobulin G (cat no. sc-2004; 1:2,000; Santa Cruz Biotechnology, Inc.) for $2 \mathrm{~h}$ at room temperature. Development was performed using an enhanced chemiluminescence detecting reagent (GE Healthcare Life Sciences, Little 
Chalfont, UK). The protein blots were quantified by densitometry using QuantityOne software version 4.6.2 (Bio-Rad Laboratories, Inc., Hercules, CA, USA), and the amounts were expressed relative to the internal reference GAPDH.

Proliferation assay. Cell proliferation was evaluated using MTT (Sigma-Aldrich, Merck KGaA, Darmstadt, Germany). A total of 2,000 cells were seeded into each well of a 96-well plate in $100 \mu 1$ medium and incubated with or without varying concentrations of erlotinib for different times, at $37^{\circ} \mathrm{C}$ in a $5 \%$ $\mathrm{CO}_{2}$ incubator. Subsequently, cells were incubated with $20 \mu \mathrm{l}$ $5 \mathrm{mg} / \mathrm{ml} \mathrm{MTT}$ for $4 \mathrm{~h}$, and cells were lysed for $10 \mathrm{~min}$ by the addition of $200 \mu \mathrm{l}$ DMSO (OriGen Biomedical, Inc., Austin, Texas, USA). Absorbance was measured at $490 \mathrm{~nm}$ using a Rainbow microplate reader (Tecan Group, Ltd., Mannedorf, Switzerland). Cell proliferation was expressed as a percentage of the untreated control.

Apoptosis assay. Cells were cultured to $80 \%$ confluence and treated with $1 \mu \mathrm{mol} / 1$ erlotinib for $48 \mathrm{~h}$. Apoptosis was analyzed using annexin V-fluorescein isothiocyanate/propidium iodide (PI) assay following the manufacturer's instructions. The amount of phosphatidylserine on the outer surface of the plasma membrane (a biochemical alteration unique to the membranes of apoptotic cells) and the amount of PI, a dye that readily enters dead cells or cells in the late stages of apoptosis and binds DNA, although it does not bind to the plasma membrane of viable cells, were detected. Fluorescence was detected using a FACSCalibur flow cytometer by fluorescence activated cell sorting analysis, and data were analyzed using CellQuest version 3.2 software (BD Biosciences, San Jose, CA, USA). Cells with phosphatidylserine on the surface were considered to be apoptotic.

Statistical analysis. Data were obtained from at least three experiments. Values are expressed as the mean \pm standard error of the mean. Statistical analysis was preformed using SPSS version 16.0 for MicroSoft ${ }^{\mathrm{TM}}$ Windows. One-way analysis of variance was used to assess differences between groups. Duncan method was employed for pairwise comparison followed by Bonferroni correction. $\mathrm{P}<0.05$ was considered to indicate a statistically significant difference.

\section{Results}

EMT and napsin A are associated with the sensitivity of lung cancer cells to the EGFR-TKI erlotinib. Lung cancer cells H322, H358, H441, A549 (wild-type EGFR) cells (25) and HCC827 (EGFR exon 19 deletion) were cultured to $80 \%$ confluence and exposed to different concentrations of erlotinib for $48 \mathrm{~h}$. Analysis of erlotinib sensitivity was performed by cell growth inhibition evaluation using an MTT assay and cell growth curves were drawn. The half-maximal inhibitory concentration $\left(\mathrm{IC}_{50}\right)$ values of these cells were respectively calculated to be 1.0, 1.71, 1.72, 5.65 and $13.6 \mu \mathrm{mol} / 1$ (Fig. 1A). Sensitivity was defined as $>50 \%$ in vitro growth inhibition at an erlotinib concentration of $<5 \mu \mathrm{mol} / 1$; moderate sensitivity was defined as the $\mathrm{IC}_{50}$ at an erlotinib concentration between 5 and $10 \mu \mathrm{mol} / 1$; insensitivity was defined as the $\mathrm{IC}_{50}$ at an erlotinib concentration of $>10 \mu \mathrm{mol} / \mathrm{l}$. The results indicated
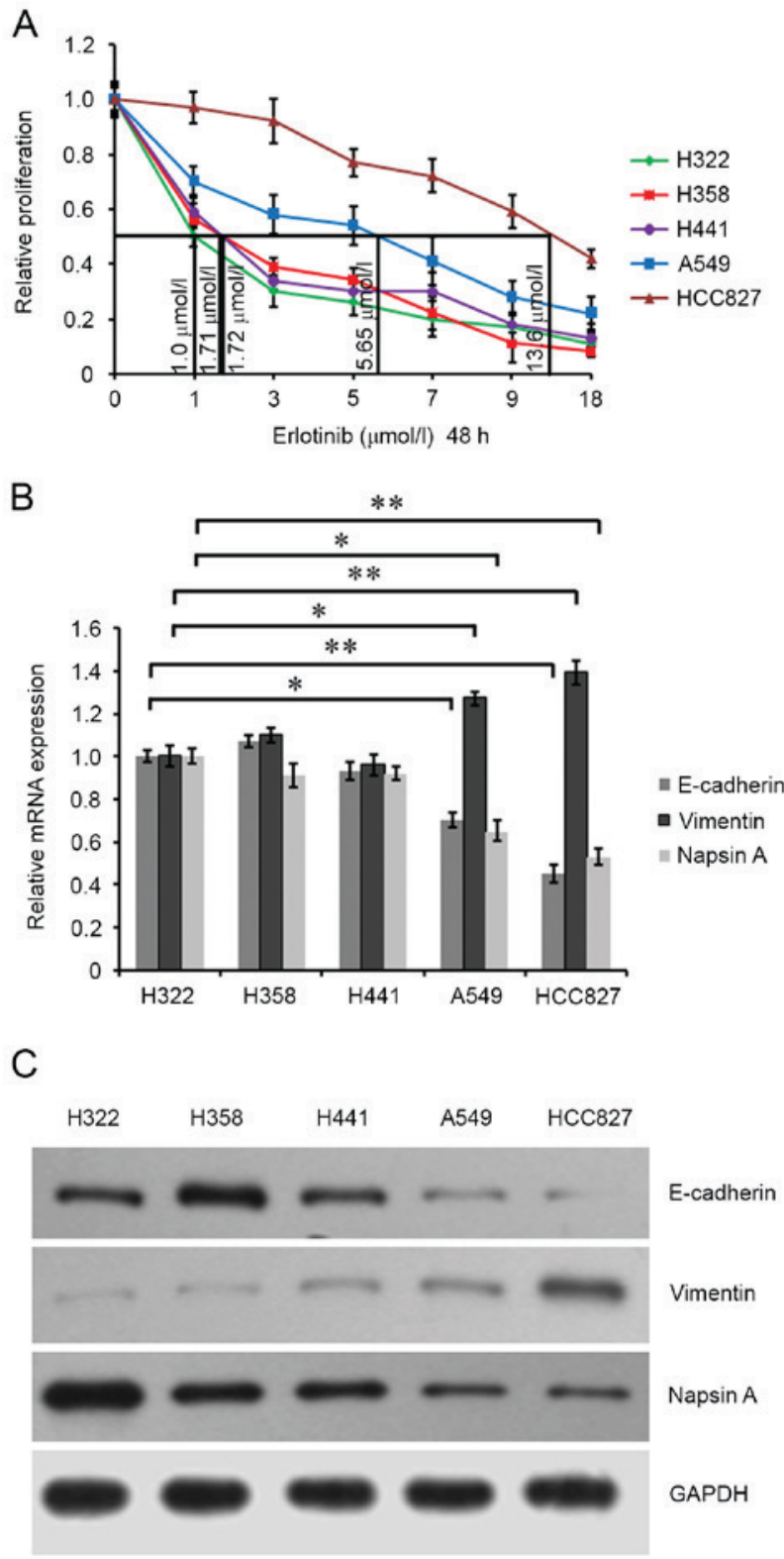

Figure 1. Characterization of lung cancer H322, H358, H441, A549 and HCC827 cells. (A) Cells were maintained in $100 \mu 1$ medium in 96-well plates for $24 \mathrm{~h}$ and exposed to $0,1,3,5,7,9$ and $18 \mu \mathrm{mol} / 1$ erlotinib for $48 \mathrm{~h}$. Cell proliferation was evaluated by MTT assay. Growth curves of the cells were drawn. Half-maximal inhibitory concentration values of the cells were calculated. (B) The mRNA expression of E-cadherin, vimentin and napsin $\mathrm{A}$ in these lung cancer cells were assessed by reverse transcription-quantitative polymerase chain reaction analysis using the corresponding primers. GAPDH was detected as an internal standard. (C) The protein expression of E-cadherin, vimentin and napsin A in cells was assessed by western blot analysis using anti-E-cadherin, anti-vimentin and anti-napsin A antibodies. GAPDH was detected as an internal standard. ${ }^{*} \mathrm{P}<0.05 ;{ }^{* *} \mathrm{P}<0.01$.

that lung cancer cells H322, H358 and H441 (wild-type EGFR) were sensitive to erlotinib, A549 (wild-type EGFR) cells were moderately sensitive, and HCC827 (EGFR exon19 deletion) cells exhibited lower sensitivity to erlotinib. Additionally, cells were treated with $1 \mu \mathrm{mol} / 1$ erlotinib for $48 \mathrm{~h}$, and the expression of EMT-associated proteins, including E-cadherin and vimentin, was detected. RT-qPCR analysis and western blotting demonstrated that erlotinib-sensitive H322, H358 and H441 cells exhibited increased E-cadherin mRNA and protein 
expression levels compared with erlotinib-moderately sensitive A549 cells and erlotinib-insensitive HCC827 cells. However, vimentin exhibited opposite expression (Fig. 1B and C). These data suggested that EMT may be associated with the sensitivity of lung cancer cells to erlotinib. Additionally, napsin A mRNA and protein expression in erlotinib-sensitive H322, H358 and H441 cells was demonstrated to be increased compared with erlotinib-moderately sensitive A549 cells, and erlotinib-insensitive HCC827 cells exhibited the lowest napsin A level, suggesting that napsin A maybe positively associated with the sensitivity of lung cancer cells to erlotinib.

Napsin A silencing enhances TGF- $\beta 1$-induced EMT. To investigate the correlation between napsin A expression and EMT in lung cancer cells, the napsin A-expressing H322 cells were used and napsin A was knocked down using siRNA technology. The mRNA and protein expression of napsin A was evaluated by RT-qPCR analysis and western blotting. The results demonstrated that napsin A expression in napsin A-silenced cells was significantly decreased compared with non-silenced control cells (Fig. 2A and B). Subsequently,cells were treated with $0,1,5,10$ and $15 \mathrm{ng} / \mathrm{ml}$ TGF- $\beta 1$ for $60 \mathrm{~h}$, and a concentration response curve for TGF- $\beta 1$ was performed. It was observed that cellular morphology began to alter when the TGF- $\beta 1$ concentration reached $5 \mathrm{ng} / \mathrm{ml}$. In addition, of the five concentrations, $5 \mathrm{ng} / \mathrm{ml}$ TGF- $\beta 1$ stimulated cell proliferation most rapidly and the EMT-associated protein levels were altered (data not shown). Therefore, $5 \mathrm{ng} / \mathrm{ml} \mathrm{TGF}-\beta 1$ was selected to induce EMT. It was demonstrated that napsin A silencing significantly enhanced the TGF- $\beta 1$-induced EMT phenotype characterized by decreased E-cadherin and increased vimentin expression in napsin A-silenced $\mathrm{H} 322$ cells compared with highly napsin A-expressing control H322 cells (Fig. 2C). $\mathrm{N}$-cadherin expression in lung cancer cells was additionally detected to be positively associated with vimentin expression in this study (data not shown).

Napsin A silencing promotes EMT-mediated erlotinib resistance. Napsin A-silenced H322 cells and control cells were respectively induced with or without $5 \mathrm{ng} / \mathrm{ml} \mathrm{TGF}-\beta 1$ for $60 \mathrm{~h}$, and subsequently treated with $1 \mu \mathrm{mol} / 1$ erlotinib for $48 \mathrm{~h}$. The cell proliferation assay demonstrated that TGF- $\beta 1$-induced EMT mediated the increased cell growth rate and resistance to erlotinib in H322 cells (Fig. 3A). However, napsin A silencing enhanced the EMT-mediated erlotinib resistance of H322 cells (Fig. 3A). In addition, the cellular apoptosis assay demonstrated that napsin A silencing attenuated the inducing effect of erlotinib on apoptosis in TGF- $\beta 1$-treated cells compared with napsin A-expressing control cells (Fig. 3B), suggesting that the expression of napsin A may inhibit EMT-mediated erlotinib resistance. These data indicated that napsin A was a potential target for improving the sensitivity of EMT-induced resistant lung cancer cells to the EGFR-TKI erlotinib.

\section{Discussion}

Lung cancer is a common malignancy with a high mortality rate, which is a severe threat to human health (1). EGFR-TKIs, including Gefitinib and erlotinib, have been used as the standard therapy in lung cancer with EGFR-activating mutations $(2,3)$. However, the majority of patients eventually

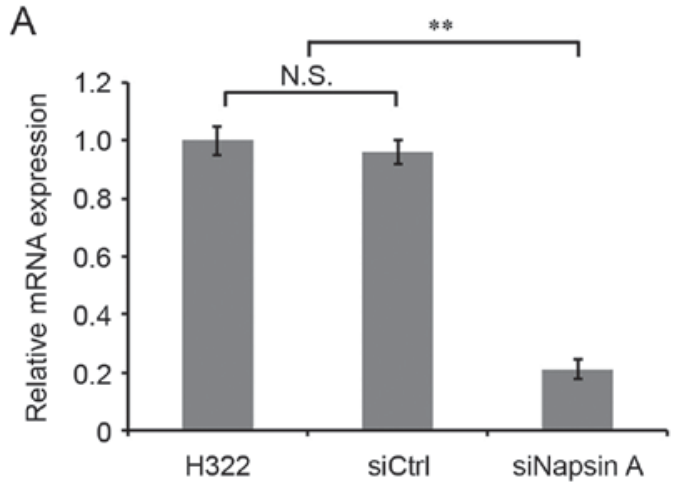

B
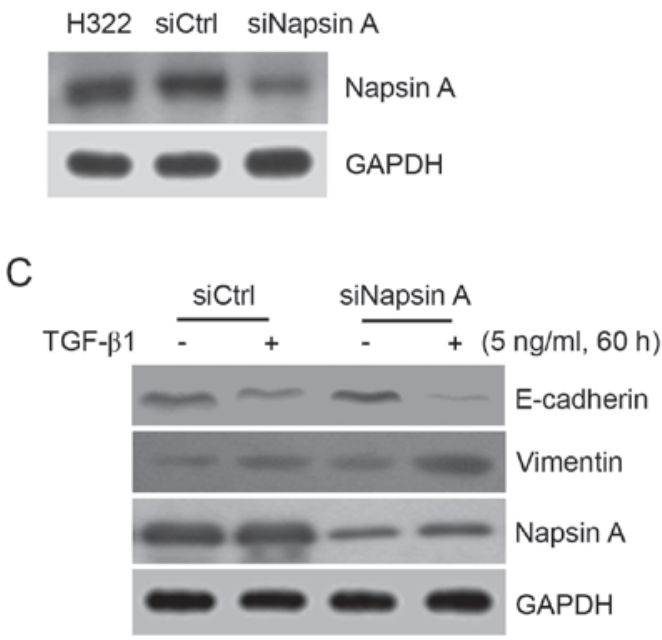

Figure 2. Effect of napsin A silencing on epithelial-mesenchymal transition-associated proteins. Cells were transfected with siCtrl or sinapsin A for $48 \mathrm{~h}$ and the (A) mRNA and (B) protein expression of napsin A cells were analyzed respectively by reverse transcription-quantitative polymerase chain reaction and western blot analyses. GAPDH was detected as an internal standard. ${ }^{* *} \mathrm{P}<0.01$. (C) napsin A-silenced and non-silenced $\mathrm{H} 322$ cells were treated with or without $5 \mathrm{ng} / \mathrm{ml}$ TGF- $\beta 1$ for $60 \mathrm{~h}$. The protein expression of E-cadherin, vimentin and napsin A in cells was assessed western blot analysis using anti-E-cadherin, anti-vimentin and anti-napsin A antibodies. GAPDH was detected as an internal standard. siCtrl, control small interfering RNA; sinapsin A, small interfering RNA for napsin A; N.S., not significant; TGF- $\beta 1$, transforming growth factor- $\beta 1$.

succumb to recurrence due to drug resistance; thus, therapeutic efficacy is markedly limited. Therefore, elucidating effective therapeutic strategies is required to overcome the acquisition of EGFR-TKI resistance. The present study demonstrated that the expression of napsin A was able to increase the sensitivity of EMT-mediated resistant lung cancer cells to erlotinib compared with napsin A-silenced cells.

EMT, defined by the combined loss of E-cadherin and the gain of mesenchymal lineage marker expression, negatively affected cellular responses to EGFR inhibitors (26). In the present study, three EGFR-TKI erlotinib-sensitive lung cancer cell lines, H358, H322 and H441, erlotinib-moderately sensitive A549 cells, and erlotinib-insensitive HCC827 cells were used and the expression of the EMT-associated proteins E-cadherin and vimentin, and the expression of napsin A, which was reported to inhibit EMT in lung cancer A549 cells (27), was detected. It was observed that E-cadherin mRNA and protein expression levels were positively associated with the sensitivity of lung cancer cells to erlotinib, while vimentin exhibited a negative 

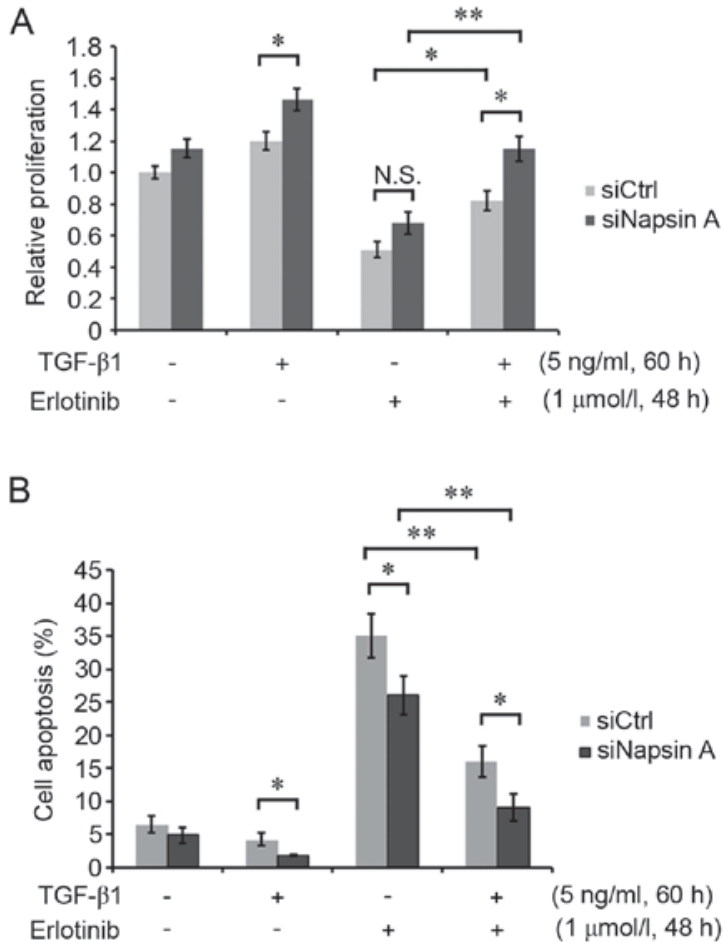

Figure 3. Effect of napsin A silencing on the sensitivity of H322 cells to erlotinib. (A) napsin A-silenced and non-silenced H322 cells were incubated with fresh medium with or without $5 \mathrm{ng} / \mathrm{ml}$ TGF- $\beta 1$ for $60 \mathrm{~h}$, and were subsequently exposed to $1 \mu \mathrm{mol} / 1$ erlotinib for $48 \mathrm{~h}$. Cell proliferation was detected by an MTT assay. (B) Cellular apoptosis was evaluated by an annexin V-fluorescein isothiocyanate/propidium iodide assay. ${ }^{*} \mathrm{P}<0.05 ;{ }^{* *} \mathrm{P}<0.01$ TGF- $\beta 1$, transforming growth factor- $\beta 1$; N.S., not significant; siCtrl, control small interfering RNA; sinapsin A, small interfering RNA for napsin A.

association with erlotinib sensitivity. Like vimentin, $\mathrm{N}$-cadherin is an important marker of EMT, commonly expressed in mesenchymal cells (28). The downregulation of E-cadherin and the upregulation of vimentin and $\mathrm{N}$-cadherin are the characteristics of EMT (9) and EMT is the underlying mechanism of acquisition of TKI resistance (5). Therefore, it was hypothesized that EMT may be involved in the development of TKI resistance in lung cancer cells. In addition, the expression level of napsin A was demonstrated to be positively associated with the sensitivity of lung cancer cells to erlotinib, suggesting that napsin A may serve an adverse role in EMT-mediated drug resistance. Therefore, highly napsin A-expressingH322 cells were used to construct a napsin A-silenced cell line using siRNA technology. Subsequently, TGF- $\beta 1$ was used to induce cellular EMT, and it was observed that TGF- $\beta 1$-treated $\mathrm{H} 322$ cells were more resistant to erlotinib compared with TGF- $\beta 1$-untreated cells. In addition, it was observed that napsin A silencing enhanced TGF- $\beta 1$-induced cellular resistance to erlotinib via proliferation and apoptosis assays, verifying the aforementioned hypothesis.

Napsin A has been reported to contain an Arg-Gly-Asp (RGD) sequence at the carboxyl terminal. The sequence is able to recognize and bind integrins on the cell surface (27). Integrins are able to mediate cell adhesion and signal transduction between cells and the ECM (29), and is an important regulator of cell proliferation, apoptosis, migration and metastasis $(30,31)$. Napsin A may suppress the interaction between Integrins and the ECM by binding Integrins, and thus inhibit the integrin-mediated signaling pathway. We have found that focal adhesion kinase 1 (FAK) was inhibited by napsin A expression in Gefitinib-resistant A549 cells (Zhou et al, unpublished data). FAK serves an important role in integrin signaling (27,32-36), and may be activated by integrin signaling and modulate a number of signaling pathways, including phosphatidylinositol 3-kinase/RAC- $\alpha$ serine/threonine-protein kinase, signal transducer and activator of transcription 1, and Ras-mitogen-activated protein kinase signaling $(32,37,38)$, and thus triggers cell growth and transformation. It was hypothesized that napsin A may repress the interaction between Integrins and ECM through RGD sequence-mediated interaction with integrin, and further inhibit the integrin signaling pathway, and cell proliferation and transformation, by downregulating FAK expression in lung cancer cells. Whether the mechanism is implicated in other lung cancer cell lines requires further investigation. Additionally, napsin A has been demonstrated to be able to suppress cell growth in 293T cells (23), and napsin A expression in systemic anaplastic large cell lymphoma (ALCL) was associated with an increased international prognostic index in malignant lymphoma; napsin A expression predicted a poor prognosis in patients with ALCL and diffuse large B-cell lymphoma (39). Therefore, these data, combined with the present finding that the expression of napsin A augmented the effect of erlotinib on TGF- $\beta 1$-induced TKI-resistant lung cancer cells, suggested that napsin A may be a promising target for improving the sensitivity of drug resistant cells, and may exhibit clinical potential.

In conclusion, the results of the present study demonstrated that napsin A served an important role in the development of EMT-mediated resistance in lung cancer cells to EGFR-TKI, and napsin A combined with EGFR-TKI may be a more effective way of improving the sensitivity of lung cancer cells to the TKI erlotinib. In order to verify the underlying resistance-associated mechanism to EGFR-TKI in vivo in human lung cancer tissues, in vivo xenograft models may be constructed by injecting different lung cancer cell lines with or without napsin A silencing into mice, and a napsin A-targeted gene treatment maybe employed in order to further assess the clinical importance and significance of the present study.

\section{Acknowledgements}

Not applicable.

\section{Funding}

No funding was received.

\section{Availability of data and materials}

The datasets used and/or analyzed during the current study are available from the corresponding author on reasonable request.

\section{Authors' contributions}

LZ, XL and ZW were major contributors in the conception and design of the research and revision of the manuscript for important intellectual content. Acquisition of data was performed by JY and YZ. TX was the major contributor in the analysis and interpretation of data and statistical analysis. Drafting of the manuscript was performed by ZW. 


\section{Ethics approval and consent to participate}

Not applicable.

\section{Consent for publication}

Not applicable.

\section{Competing interests}

The authors declare that they have no competing interests.

\section{References}

1. PDQ Adult Treatment Editorial Board. Non-small cell lung cancer treatment $(\mathrm{PDQ} \otimes)$ : Patient version. NCI. May 12, 2002-2015.

2. Soria JC, Mok TS, Cappuzzo F and Jänne PA: EGFR-mutated oncogene addicted non-small cell lung cancer: Current trends and future prospects. Cancer Treat Rev 38: 416-430, 2012.

3. Nguyen KS and Neal JW: First-line treatment of EGFR-mutant non-small cell lung cancer: The role of erlotinib and other tyrosine kinase inhibitors. Biologics 6: 337-345, 2012.

4. Pao W, Miller VA, Politi KA, Riely GJ, Somwar R, Zakowski MF, Kris MG and Varmus H: Acquired resistance of lung adenocarcinomas to Gefitinib or erlotinib is associated with a second mutation in the EGFR kinase domain. PLoS Med 2: e73, 2005.

5. Wu PF, Zhu YP, Yang CH, Wang YF and Wang GH: The mechanism and countermeasures on the secondary resistance of epidermal growth factor receptor tyrosine kinase inhibitor (EGFR-TKI). Anti Tumor Pharmacy 5: 4, 2015.

6. Thiery JP, Acloque H, Huang RY and Nieto MA: Epithelial-mesenchymal transitions in development and disease. Cell 139: 871-890, 2009.

7. Yang J and Weinberg RA: Epithelial-mesenchymal transition At the crossroads of development and tumor metastasis. Dev Cell 14: 818-829, 2008.

8. Guarino M, Rubino B and Ballabio G: The role of epithelial-mesenchymal transition in cancer pathology. Pathology 39: 305-318, 2007.

9. Robert G, Gaggioli C, Bailet O, Chavey C, Abbe P, Aberdam E, Sabatié E, Cano A, Garcia de Herreros A, Ballotti R and Tartare-Deckert S: SPARC represses E-cadherin and induces mesenchymal transition during melanoma development. Cancer Res 66: 7516-7523, 2006

10. Voulgari A and Pintzas A: Epithelial-mesenchymal transition in cancer metastasis: Mechanisms, markers and strategies to overcome drug resistance in the clinic. Biochim Biophys Acta 1796: 75-90, 2009.

11. Neel DS and Bivona TG: Secrets of drug resistance in NSCLC exposed by new molecular definition of EMT. Clin Cancer Res 19: 3-5, 2013.

12. Uramoto $H$, Iwata $T$, Onitsuka $T$, Shimokawa $H$, Hanagiri $T$ and Oyama T: Epithelial-mesenchymal transition in EGFR-TKI acquired resistant lung adenocarcinoma. Anticancer Res 30: 2513-2517, 2010.

13. Yao Z, Fenoglio S, Gao DC, Camiolo M, Stiles B, Lindsted T, Schlederer M, Johns C, Altorki N, Mittal V, et al: TGFb IL-6 axis mediates selective and adaptive mechanisms of resistance to molecular targeted therapy in lung cancer. Proc Natl Acad Sci USA 107: 15535-15340, 2010.

14. Tatnell PJ, Powell DJ, Hill J, Smith TS, Tew DG and Kay J: Napsins: New human aspartic proteinases. Distinction between two closely related genes. FEBS Lett 441: 43-48, 1998.

15. Brasch F, Ochs M, Kahne T, Guttentag S, Schauer-Vukasinovic V, Derrick M, Johnen G, Kapp N, Muller KM, Richter J, et al: Involvement of napsin $\mathrm{A}$ in the $\mathrm{C}$ - and $\mathrm{N}$-terminal processing of surfactant protein B in type-II pneumocytes of the human lung. J Biol Chem 278: 49006-49014, 2003.

16. Ueno T, Linder S, Na CL, Rice WR, Johansson J and Weaver TE: Processing of pulmonary surfactant protein $\mathrm{B}$ by napsin and cathepsin H. J Biol Chem 279: 16178-16184, 2004.

17. Suzuki A, Shijubo N, Yamada G, Ichimiya S, Satoh M, Abe S and Sato N: Napsin A is useful to distinguish primary lung adenocarcinoma from adenocarcinomas of other organs. Pathol Res Pract 201: 579-586, 2005.
18. Chuman Y, Bergman A, Ueno T, Saito S, Sakaguchi K, Alaiya AA, Franzén B, Bergman T, Arnott D, Auer G, et al: Napsin A, a member of the aspartic protease family, is abundantly expressed in normal lung and kidney tissue and is expressed in lung adenocarcinomas. FEBS Lett 462: 129-134, 1999.

19. Schauer-Vukasinovic V, Bur D, Kling D, Grüninger F and Giller T: Human napsin A: Expression, immunochemical detection, and tissue localization. FEBS Lett 462: 135-139, 1999.

20. Hirano T, Auer G, Maeda M, Hagiwara Y, Okada S, Ohira T, Okuzawa K, Fujioka K, Franzén B, Hibi N, et al: Human tissue distribution of TA02, which is homologous with a new type of aspartic proteinase, napsin A. Jpn J Cancer Res 91: 1015-1021, 2000.

21. Hirano T, Gong Y, Yoshida K, Kato Y, Yashima K, Maeda M, Nakagawa A, Fujioka K, Ohira T, Ikeda N, et al: Usefulness of TA02 (napsin A) to distinguish primary lung adenocarcinoma from metastatic lung adenocarcinoma. Lung Cancer 41: 155-162, 2003.

22. Ueno T, Linder S and Elmberger G: Aspartic proteinase napsin is a useful marker for diagnosis of primary lung adenocarcinoma. Br J Cancer 88: 1229-1233, 2003.

23. Ueno T, Elmberger G, Weaver TE, Toi M and Linder S: The aspartic protease napsin A suppresses tumor growth independent of its catalytic activity. Lab Invest 88: 256-263, 2008.

24. Slack JL, Bi W, Livak KJ, Beaubier N, Yu M, Clark M, Kim SH, Gallagher RE and Willman CL: Pre-clinical validation of a novel, highly sensitive assay to detect PML-RARalpha mRNA using real-time reverse-transcription polymerase chain reaction. J Mol Diagn 3: 141-149, 2001

25. Thomson S, Buck E, Petti F, Griffin G, Brown E, Ramnarine N, Iwata KK, Gibson N and Haley JD: Epithelial to mesenchymal transition is a determinant of sensitivity of non small cell lung carcinoma cell lines and xenografts to epidermal growth factor receptor inhibition. Cancer Res 65: 9455-9462, 2005.

26. Grunert S, Jechlinger M and Beug H: Diverse cellular and molecular mechanisms contribute to epithelial plasticity and metastasis. Nat Rev Mol Cell Biol 4: 657-665, 2003.

27. Zheng JX, Guan SH, Xu Q, Liu JZ and Song P: Inhibition of epithelial-mesenchymal transitionin A549 cell by transfected Napsin A. Chin Med J (Engl) 125: 2734-2740, 2012.

28. Nakajima S, Doi R, Toyoda E, Tsuji S, Wada M, Koizumi M, Tulachan SS, Ito D, Kami K, Mori T, et al: N-cadherin expression and epithelial-mesenehymal transition in pancreatic carcinoma. Clin Cancer Res 10: 4125-4133, 2004.

29. Ruoslahti E: RGD and other recognition sequences for integrins Annu Rev Cell Dev Biol 12: 697-715, 1996.

30. Juliano RL: Signal transduction by cell adhesion receptors and the cytoskeleton: Functions of integrins, cadherins, selectins, and immunoglobulin-superfamily members. Annu Rev Pharmacol Toxicol 42: 283-323, 2002.

31. Hynes RO: Integrins: Bidirectional, allosteric signaling machines. Cell 110: 673-687, 2002.

32. Li Y, Yang J, Dai C, Wu C and Liu Y: Role for integrin-linked kinase in mediating tubular epithelial to mesenchymal transition and renal interstitial fibrogenesis. J Clin Invest 112: 503-516, 2003.

33. Bhowmick NA, Zent R, Ghiassi M, McDonnell M and Moses HL: Integrin beta 1 signaling is necessary for transforming growth factor-beta activation of p38MAPK and epithelial plasticity. J Biol Chem 276: 46707-46713, 2001.

34. Hauck CR, Sieg DJ, Hsia DA, Loftus JC, Gaarde WA, Monia BP and Schlaepfer DD: Inhibition of focal adhesion kinase expression or activity disrupts epidermal growth factor-stimulated signaling promoting the migration of invasive human carcinoma cells. Cancer Res 61: 7079-7090, 2001

35. Sieg DJ, Hauck CR, Ilic D, Klingbeil CK, Schaefer E, Damsky CH and Schlaepfer DD: FAK integrates growth-factor and integrin signals to promote cell migration. Nat Cell Biol 2: 249-256, 2000.

36. Sieg DJ, Hauck CR and Schlaepfer DD: Required role of focal adhesion kinase (FAK) for integrin-stimulated cell migration. J Cell Sci 112: 2677-2691, 1999.

37. Hauck CR, Hsia DA and Schlaepfer DD: The focal adhesion kinase a regulator of cell migration and invasion. IUBMB Life 53: 115-119, 2002.

38. Xie B, Zhao J, Kitagawa M, Durbin J, Madri JA, Guan JL and Fu XY: Focal adhesion kinase activates Stat1 in integrin-mediated cell migration and adhesion. J Biol Chem 276: 19512-19523, 2001.

39. Nam SJ, Kim S, Kim JE, Lim MS, Elenitoba-Johnson KS, Kim CW and Jeon YK: Aberrant expression ofnapsinA in a subset of malignant lymphomas. Histol Histopathol 31: 213-221, 2016. 